\title{
Extrapolative Morph Design Thinking as an Intangible Ecological Form to Encode the Ecodesign Identity
}

\author{
Mohd Hasni Chumiran 1, Shahriman Zainal Abidin 1, Rusmadiah Anwar 1, Hassan Alli 2 \\ 1 Department of Industrial Design, Faculty of Art and Design, Universiti Teknologi MARA, 40450 Shah Alam, Malaysia \\ 2 Department of Industrial Design, Faculty of Design and Architecture, Universiti Putra Malaysia, 43400 Serdang, Malaysia \\ hasniide@yahoo.com, shahriman.z.a@salam.uitm.edu.my, rusma935@salam.uitm.edu.my, halli@upm.edu.my \\ $+60132855448$
}

\begin{abstract}
This paper identifies a new distinction of ecodesign form, where it emerged from the literature case study that most practising designers have not conceived to interpret design research as an ecodesign identity. This research article objective reveals the ecological form creation in the semantics orders. The imaging product digitized an ecological form that was hermeneutically sourced by the literature review process using the heuristic method. It digitized the visual imagery before entering the prescriptive stage. The product imagery therefore digitized some ecodesign characteristics that the intangible ecological form conveyed in the form follows functional perspective; believing to environmentally-friendly product design.
\end{abstract}

Keywords: Form; heuristic method; industrial design; intangible ecological form

eISSN: 2398-4287@ 2020. The Authors. Published for AMER ABRA cE-Bsby e-International Publishing House, Ltd., UK. This is an open access article under the CC BYNC-ND license (http://creativecommons.org/licenses/by-nc-nd/4.0/). Peer-review under responsibility of AMER (Association of Malaysian Environment-Behaviour Researchers), ABRA (Association of Behavioural Researchers on Asians) and cE-Bs (Centre for Environment-Behaviour Studies), Faculty of Architecture, Planning \& Surveying, Universiti Teknologi MARA, Malaysia.

DOI: https://doi.org/10.21834/ebpj.v5iSl3.2538

\subsection{Introduction}

Fundamentally, the structure of a sustainable product design (SPD) comes explicitly from the understanding of new product development (NPD). The engineering design (ED) field has successfully introduced and established the design principles following the industrial cycle of knowledge through the principles of the design area, domain and the body of knowledge (Chumiran, Abidin, \& Sirat, 2016).

This study focused on the concept of product form to identify an intangible ecological form of the ecodesign identity within its fundamental approach practices to produce an industrial cycle roadmap using the concept of SPD. This research explored the emergence of a formgiving phenomena enquiry from the bipolar geometry form to the organic form, as coined by the formgiving expert, Akner-Koler (2007).

In this study, we intuitively developed the ecological design eyesight (semantics design thinking perspective) using the heuristic method and approach understanding that can morph an intangible ecological form of the ecodesign identity. The structure of the paper is as follows: (1) introduction, (2) background, (3) method, (4) results and discussion, and (5) conclusion. However, we aimed to apply the metaphorical patterns from the bipolar geometry form to the organic form (Akner-Koler, 2007) following the metaphor of semantics design thinking to present an exact formgiving design image, which reflects the importance of the ecodesign identity concept.

eISSN: 2398-4287@ 2020. The Authors. Published for AMER ABRA cE-Bsby e-International Publishing House, Ltd., UK. This is an open access article under the CC BYNC-ND license (http://creativecommons.org/licenses/by-nc-nd/4.0). Peer-review under responsibility of AMER (Association of Malaysian Environment-Behaviour Researchers), ABRA (Association of Behavioural Researchers on Asians) and cE-Bs (Centre for Environment-Behaviour Studies), Faculty of Architecture, Planning \& Surveying, Universiti Teknologi MARA, Malaysia.

DOI: https://doi.org/10.21834/ebpj.v5iSI3.2538 


\subsection{Background}

In this qualitative background study, we used the typological design families to translate and gather the intangible form of the ecodesign identity interpretation context (Oxman, 2008; Abidin, 2012). Thus, we coined the term "typological design mapping" to refer to the pattern of the metaphorical, articulated design distinction that could be presented in a "flattened-out" view of thinking according to each artefact's design movement era sequentially (Thomas, 2011). Consequently, this study categorised the design pattern era following the related structure of history timeline branches. Based on the intuition of semantics study, the product form creation is divided into two categories, namely (1) the tangible form creation and (2) the intangible form creation, as depicted in Figure 1 and Figure 2, respectively.

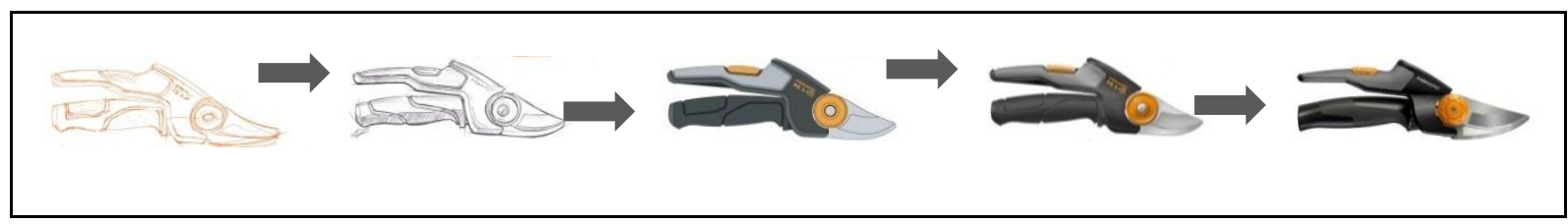

Fig. 1: Tangible form creation (using the interpolative strategy)

(Mondo sketches - Fiskars ${ }^{1}$ )

The tangible form refers to the explicit semantics design development from the product form's foundation using "direct" visual and/or mass production physically, popularly known as an interpolative strategy (Abidin, 2012). Meanwhile, the intangible form represents the implicit semantics design development from the product form's fusion through an "indirect" ecological system of an artefact's timeline environmentally as well as 'beyond continuum' from one of the control images by using the extrapolative strategy (Abidin, 2012).

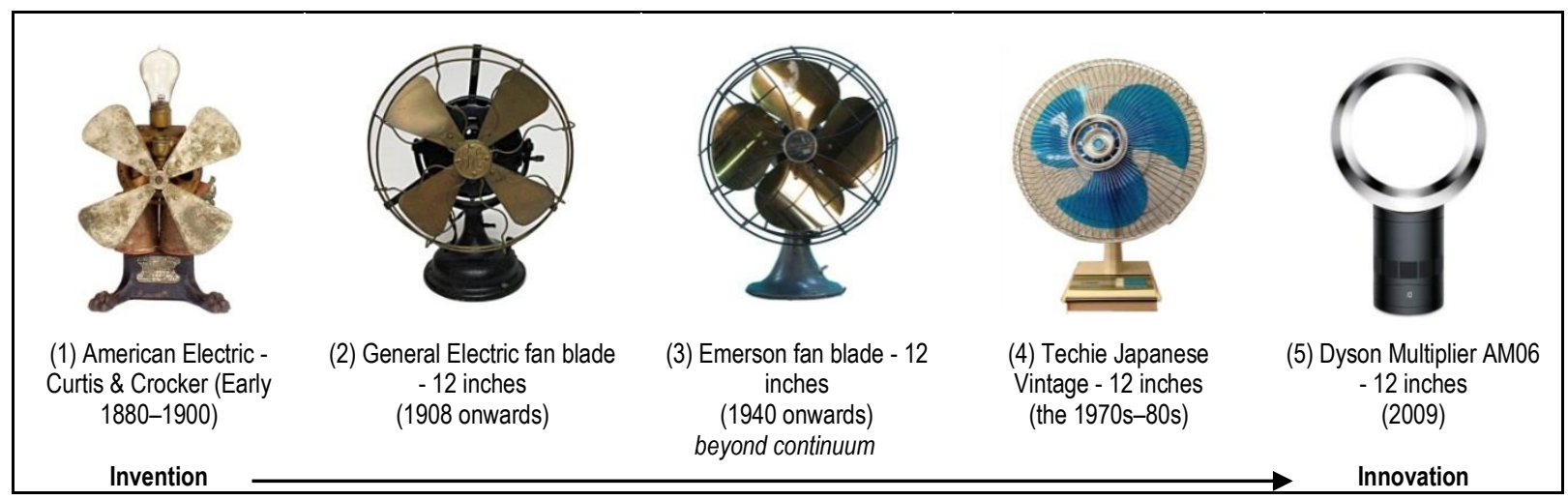

Fig. 2: Intangible form creation (using the extrapolative strategy)

(A case study of the extrapolative strategy ${ }^{2}$ )

For the ecodesign identity imagination to emerge, the intangible ecological form sources should be engaged (from bipolar to beyond continuum) in two different design areas involving (1) a form that follows function from the designer's practices in the industrial design (ID) field and (2) a cantilever principle design from the engineer's disciplines in the engineering design field (ED). Both fields can be hermeneutically combined concurrently to understand an artefact's quality review within its ecodesign identity concept - the heuristic approach (Chumiran, Abidin, \& Sirat, 2016). These two design outlines could assist product designers, as they are common practice in the product form concept, as described below:

\subsection{Form Follows Function}

An object's form in industrial design (ID) is revealed through the key design concept, as in the well-known principle of "form follows function" introduced by the modern architect-designer, Louise Sullivan (Crilly, 2005: Mehlhose \& Wellner, 2012). This design concept theme has inspired and influenced many designers in addressing a particular product design development (Abidin, 2012; Jamaludin, Zulkapli, \& Zainal Abidin, 2013). Under the SPD development, the engineering design field or/and system has assigned the form of object design as always being dependent on the material used from material streams I, II, III and IV (Cramer, 1997). The right material selection involves the criteria, characteristics and capability (3C's) of an ecological form system (Chumiran, Abidin, \& Sirat, 2014). From the ID perspective, Abidin (2012) stated that the material used can be visualised through a semiotic understanding, which is

\footnotetext{
1 Interpolative Source: PowerGear Pruner by Colin Roberts at Coroflot.com.

2 Extrapolative Sources: (1) https://americanhistory.si.edu/lighting/c_choice/choice_3a.htm, (2) https://earlyfans.blogspot.my/2011/02/ge-pancake-1894-1908.html, (3) https://www.fancollectors.org/Emerson2/emerson2.htm, (4) https://www.etsy.com/listing/159003739/techie-japanese-vintage-electricfan?show_sold_out_detail=1, and (5) https://www.theguardian.com/technology/2014/jul/18/dyson-cool-am06-review-desk-fan.
} 
associated with the semantics design thinking scientifically. He agreed with Monö (1997) that semiotics means "the study of signs and sign systems, their structure, properties and role in socio-cultural behaviour" (p. 11). In defining a design object, Abidin preferred to use the fundamental entities of visual elements (VE), which means a few materials can be screened and/or outlined with the combination of two dimensional (2D) and three dimensional (3D) forms simultaneously. A notable example provided by the historical Bauhaus in the ID field is an earlier interpretation of the product form, the first cantilever design concept by the famous architectdesigner of the Bauhaus era, Mart Stam. According to Mácel (1990), Mart Stam's "power of form" has brought a considerable impact on the sustainability scale, ecological eyesight and future perspective until the present day. In the product form study, he demonstrated the principle of the steel tube cantilever, following the VE creation of the form follows function concept and influenced by architecture's dramatic interpretation (Crilly, 2005; Abidin, 2012; Jamaludin, Zulkapli, \& Zainal Abidin, 2013; Chumiran, Abidin, \& Sirat, 2016)

\subsection{Cantilever principle concept addressed by the design principle theory}

The propped cantilever form originates from the beam model or beam equations principle. The scientist, Leonardo da Vinci, introduced it in the $14^{\text {th }}$ century through a publication in Codex Madrid I. In the $18^{\text {th }}$ century, it was addressed again by Daniel Bernoulli, who popularised the traditional Euler-Bernoulli beam theory in 1750 (Chumiran, Abidin, \& Sirat, 2016). Bischoff et al. (2004) stated that today, the beam theory is used in many knowledge disciplines, such as mechanical engineering, structural engineering, and engineering design technology (Chumiran, Abidin, \& Sirat, 2016). The Dictionary of Architecture and Construction provides two meanings for "cantilever", which are (1) "a beam, girder, truss, or structural member or surface that projects horizontally beyond its vertical support, such as a wall or column" and (2) "a projecting bracket used for carrying the cornice or extended eaves of a building" (Harris, 2006, p.169) (see Figure 3).

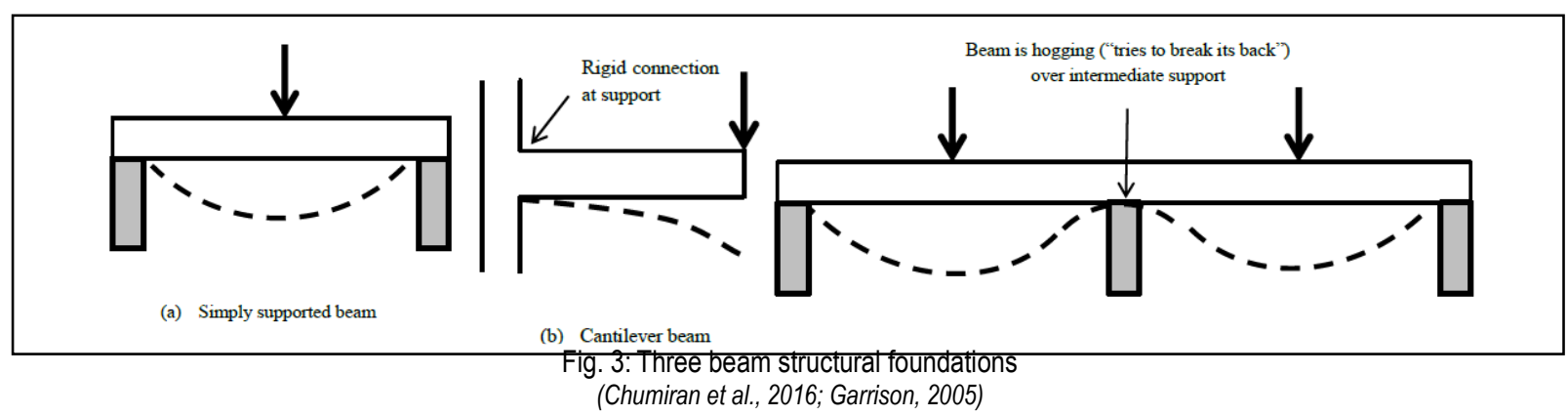

Therefore, from both meanings, the word project serves as the keyword in highlighting the cantilever principle design due to the form's characteristic, which addresses the interrelation with the basic beam theory and Euler-Bernoulli's beam theory interpretation. The artefact's design history encodes Mart Stam's cantilever principle concept (steel tube design) in the conventional architectural design.

\subsection{Method}

Initially, we physically displayed a modern classics furniture to project the sequence of an ecological form movement using the heuristic method. It can be traced in the images of VE and form evolution from the observation study (using the morphing study) within the topology approach (Oxman, 2008; Abidin, 2012).

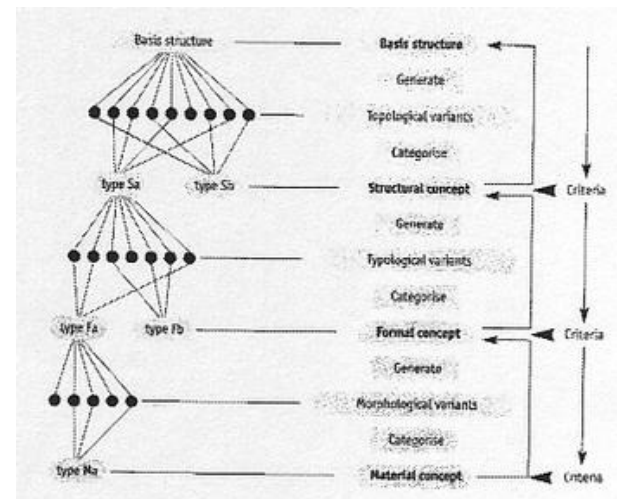

Fig. 4: Form evolution screened a small design sample using the typological level study approach (Abidin, 2012: Muller, 2001) 
First, we used Mart Stam's cantilever design concept and put the artefact in the middle to create a five-rank scale in order to measure the quality of form evolution from the bipolar geometry form to the organic form. Next, 48 design samples ${ }^{3}$ (enquiries) were collected from the timeline history of the book case study. It had remarkably inspired us to develop a typological pattern search, and its function is to indicate and classify some forms' topology in a typological search study (Thomas, 2011). Here, this study gathered and sorted the artefacts' design patterns based on the classification of the design movement era - artefact design pattern (the history of Art Nouveau Furniture from 1859 to the Postmodern era to today) by using the typology method (Mehlhose \& Wellner, 2012). The 852 design patterns of the modern design furniture were identified and categorised thematically to the 440 designers that designed the patterns. Homogeneous characteristic $(\mathrm{HC})$ was used to obtain the actual number of small design samples. At this stage, the $\mathrm{HC}$ of the cantilever principle concept was required for the thematic process, where the branching of the typological design families sorted and layered the final design samples by following the levelling structural components sequentially (See Figure 4). However, this design method study found a limitation in the design experience as the concept of pictorial digitisation follows the extrapolative design thinking. Therefore, the qualitative methodology should use induction reasoning.

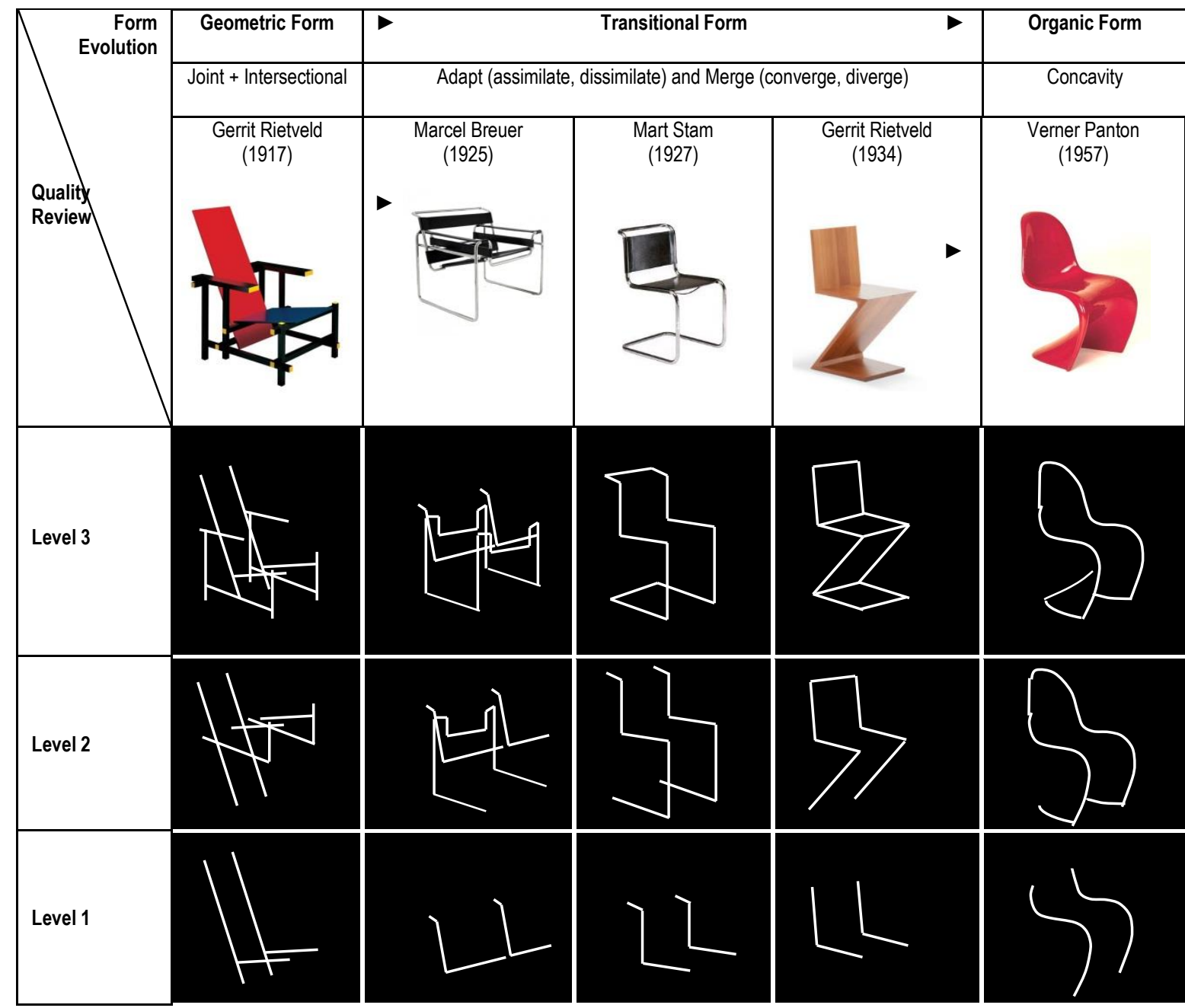

Fig. 5: Heuristic quality review - a procedural step (Chumiran et al., 2016)

In screening the cantilever principle concept, Garisson (2005) elaborated that the beam model defines three kinds of beam structural foundations, which are simply-supported beam, continuous beam, and cantilevered beam (Chumiran, Abidin, \& Sirat, 2016). As depicted in Figure 3 above, he illustrated the simple 2D outline images to derive the form's characteristic. The dashed line demonstrates that the beam's structure will bend and lay down the moment that the maximum load is put on the linear beam form. This demonstration is crucial to designers, as they could use their imagination to conduct the product form in the ecodesign concept creation. It means that the VE has recognised the cantilever principle concept to address the images and form, concurrently generated in two dimensions and three dimensions (Abidin, 2012). Then, each artefact was categorised within the design movement era morphologically (Oxman, 2008; Thomas, 2011; Mehlhose \& Wellner, 2012). At this stage, we used the linkage notation to demonstrate

\footnotetext{
3 Design sample sources: the study used a book case study (Modern Furniture: 150 Years of Design - moderne Möbel: 150 Jahre Design). It identified the extrapolative design thinking, which consistently assigns the number of design samples using homogeneous characteristic and the design theme itself.
} 
the design patterns in every cluster of artefacts, where the pathway sequence had created a supply chain direction. Therefore, this metaphor method approach is established from the ecological design generated from the cognitive model (CM) in the CM of ecology (Krippendorff, 1989). Hence, the entire metaphorical data collection conveys the epistemology of the ecodesign identity theory within the design mythology itself.

In evaluating and examining the use of the typology method, as shown in Figure 5, the number of lines represents the actual number of the component structures and their functions. Hence, the sitting chair designs were gradually reduced following three functional units (a chair's components), namely (1) leg support, (2) seat structure, and (3) backrest structure, sequentially. As for the recycling method, it refers to the number of materials used and their selection, beginning from wooden to multiple materials to resin plastic. Thus, the single resin plastic allows the reuse of resin plastic as indicated by the resin code (3R's mobius loop cycle) (Abidin, 2012; Jamaludin, Zulkapli, \& Zainal Abidin, 2013; Chumiran, Abidin, \& Sirat, 2016) Therefore, this qualitative evaluation (heuristic case study) reveals the extrapolative strategy through the framing structure, which has been consistently demonstrated by the artefacts' form evolution.

\subsection{Results and Discussion}

In the Method section, we have delivered an analysis based on the heuristic case study (artefact images) that the significant quality of the metaphor design pattern influences the ecodesign identity's creation.

\subsection{Gestalt theory on the aesthetics of the ecodesign identity's concept}

A psychology literature study is required to understand the "design concept" context, and it is referred to as Gestalt Psychology (GP). In 1912, GP was introduced by Max Wertheimer through his modern psychology during the visual perception research known as the phi motion study. Using visual perception, he successfully established the critical findings that a sketch development demonstrates seven logical principles, namely proximity, similarity, common fate, good continuation, closure, symmetry, and parallelism (Arnheim, 1949; Wagemans et al., 2012; Abidin, 2012;). To capture the visual perception research in GP, Akner-Koler highlighted the need to understand the "laws of organisation in the perception of forms" that was introduced by Max Wertheimer in 1924 (Akner-Koler, 2007 ; Chumiran, Abidin, \& Sirat, 2016). Wertheimer's perceptual study shows the relationships of the 2D elements representing the 3D object as a whole identify. Wagemans et al. (2012) suggested using the camouflage approach in defining the 3D object's form with perceptual grouping (Akner-Koler, 2007; Chumiran, Abidin, \& Sirat, 2016). Wagemans et al. (2012, p. 1180) defined camouflage as:

\footnotetext{
...when the same grouping processes that would normally make an organism stand out from its environment as a separate object cause it to be grouped with its surroundings instead. For instance, the same leopard that is visible when it is seen in a tree against the uniform sky is difficult to see against a mottled, leafy backdrop-until it moves.
}

Therefore, to simplify the fundamental understanding of GP concerning an object's or thing's imagery related to beauty, it means the nature of aesthetics is to imply a visual appearance or a product's form (case study) with differences in the styling approach that it scientifically branches to the emotion of human psychology (Arnheim, 1949; Krippendorff, 1989; Crilly, 2005; Abidin, 2012).

\subsection{R's method recognises the intangible formgiving identification}

As can be observed in Figure 5, the cantilever design principle has interpreted the extrapolative elementary using the heuristic procedural step. From here, the case study defined and identified the "Reduce, Reuse and Recycle" (3R's) method validation, which was revealed by the simplicity of the form's characteristic movement that it impacted the reduction and minimisation of the materials used, the stages of the manufacturing process, and the fabrication work implicitly. We found that the mobius loop cycle of the 3R's method dominantly influences how product designers re-think designs to comply with the criteria, capability and characteristics (3C's) of the ecological system (Chumiran, Abidin, \& Sirat, 2016). For example, the evaluation of the bipolar geometric form and the organic form was via the horizontal continuum's transitional form of object qualities, which is represented by the X-axis. Meanwhile, vertically, the $Y$-axis indicates the value or/and number of levels in the observation study. At this stage, the intuitive semiotics experience by the product designers will morph the form pattern evolution that it could be screened as an intangible ecological form of ecodesign by the heuristic quality review approach. Hence, a dual semantics design thinking (X-axis and Y-axis) crucially examines the extrapolative intangible formgiving identification.

\subsection{Achievement of the Sustainable Development Goal by the environment of visual elements development}

The environment of VE of the ecodesign identity context has implicitly occurred in Figure 5 . There is an awareness about producing a recycled product (in the design artefact context), and it has allowed an environment of VE approach simultaneously. For instance, in the history of design evolution morphology, the twentieth-century cantilever chair design concept that followed the cantilever principle design (from 1917 until 1957) was formed with ecological relevance; an ecological form of the four-legged chair was structured by the De Stijl designer, Gerrit Rietveld, minimising it into a sitting chair and many years later, the last designer, Verner Panton, demonstrated an exact product form identity (Chumiran, Abidin, \& Sirat, 2016). Hence, an impact of beyond continuum reflects the semantics design thinking logically, which happens due to the environmental ecology of the designer's mind (Krippendorff, 1989). 
Therefore, in the new design movement era, the beyond continuum characteristic has delivered a supply chain cycle and closed-loop green technology. Also, recently, designers have been exposed to the "Sustainable Development Goal" (SDG) and have started to evaluate the ecodesign product forms. It will be beneficial to apply their understanding in the design of consumer products and practice of closed-loop cycle methodology as a holistic descriptivism of a person's behavioural response within the SPD thinking (Chumiran, Abidin, \& Sirat, 2016).

\subsection{Conclusion}

In this ecodesign identity study, the extrapolative design thinking can symbiotically embody the quality of design artefacts by using two design mechanism outlines, namely (1) form follows function and (2) cantilever principle design. The analogy of design sampling (imagery) emerged from the fundamental ways of communicating in design, which was introduced by Rune Monö (1997). The study has interpreted the meanings in Abidin (2012), which suggested four types of semantics function from the Monö model processes as well as (1) describing, (2) expressing, (3) exhorting and (4) identifying; it developed a design communication to introduce an aesthetic of the ecodesign identity outcome hermeneutically. For the findings on impact, the semiotics sign has encouraged many product designers (ID field) and design engineers (ED field) to use the pictorial formgiving qualities from the visual aid digitisation and data sources of networking communication. These two computing components allow easy tracing of the imagery data of the ecodesign identity. These two component are well known with the pictographic image under the visual digitisation via design experience. Implicitly, in the manual mode, since designers have intensely practised the designing model process in the ecology of their minds, the form design mythology eyesight is conveyed spontaneously (Krippendorff, 1989). Furthermore, this metaphor study has addressed a crucial new challenge in design education to adopt and adapt into the digital innovation practice called "Cyber-Physical Systems" (CPS) along with the phenomenal global Fourth Industrial Revolution (Industry 4.0) movement era (Brandmeiera et al., 2016). Therefore, our future work will discover the metaphor of extrapolative morph design thinking using a prescriptive study according to the design research methodology (DRM) framework. This study is manual extrapolative sketching that investigated the qualities of product form identity in a morphing study, which can be systematically interpreted using the scientific research methodology. However, it is challenging for product designers to compare some metaphor design patterns. Thus, there will be a reduced knowledge gap in the semantics of object qualities as well.

\section{Acknowledgements}

This research is financially supported by the Institute of Research Management \& Innovation (IRMI), Universiti Teknologi MARA (UiTM), Malaysia - No.: 600-IRMI/MyRA 5/3/REI (002/2018). This support is gratefully acknowledged.

\section{References}

Abidin, S. Z. (2012). Practice-based Design Thinking For Form Development and Detailing, Trondheim, (Norwegian University of Science and Technology).

Akner-Koler, C. (2007). Form and Formlessness, Sweden, (the Chalmers University of Technology and University College of Arts).

Arnheim, R. (1949). The Gestalt theory of expression. Psychological Review, 56(3), 156-171.

Brandmeiera, M., Bognera, E., Brossoga, M. \& Frankea, J. (2016). Product design improvement through knowledge feedback of cyber-physical systems, 26th CIRP Design Conference, Procedia CIRP 50, 186 - 191.

Chumiran, M. H., Abidin, S. Z., \& Sirat, A. (2016). The Impact of 3R's Element Creation on Ecological Form of Ecodesign in Malaysia. Shah Alam, (MA Thesis, Universiti Teknologi MARA).

Chumiran, M. H., Abidin. S.Z. \& Sirat, A. (2014). The Environmental-driven Elements Towards Ecological Systems of Furniture Design, 2nd TIME-E 2014 International Conference, 141-146.

Cramer, J. (1997). Towards innovative, more eco-efficient product design strategies. The Journal of Sustainable Product Design, Issue 1, 7-16.

Crilly, N. (2005). Product Aesthetics: representing designer intent and consumer response, Cambridge, (University of Cambridge).

Jamaludin, M. S. Zulkapli, M. F. \& Zainal Abidin, S. The Characteristics of Form in Relation to Product Emotion, the 15th International Conference on Engineering and Product Design Education (E\&PDE2013), DS 76, Dublin, 2013, pp. 716-721.

Krippendorff, K. (1989). Product Semantics '89, Product Semantics: A Triangulation and Four Design Theories,1-32.

Mehlhose, A. \& Wellner, M. (2012). Modern Furniture: 150 Years of Design - moderne Möbel:150 Jahre Design, Berlin, Germany, (Éditions H. F. Ullmann).

Oxman, R. (2008). Digital architecture as a challenge for design pedagogy: theory, knowledge, models and medium, Design Studies, Volume 29, No. 2, 99-120.

Thomas, G. (2011). A Typology for the Case Study in Social Science Following a Review of Definition, Discourse, and Structure, I7(6), 511-521. 
Chumiran, M.H., et.al., CSSR2018, 5th International Conference on Science and Social Research, Le Meridien Kota Kinabalu Hotel, 5 - 6 Dec 2018, E-BPJ, 5(SI3), Dec 2020 (pp.91-97)

Wagemans, J., Elder, J. H., Kubovy, M., Palmer, S. E., Peterson, M. A., Singh, M., \& von der Heydt, R. (2012). A Century of Gestalt Psychology in Visual Perception: I. Perceptual Grouping and Figure-ground Organization. Psychological Bulletin, 138(6), 1172-1217. 